\title{
Fine Mapping and Identification of Blast Resistance Gene Pi-hkI in a Broad-Spectrum Resistant japonica Rice Landrace
}

\author{
Yunyu Wu, Yongmei Bao, Liujie Xie, Yunyun Su, Ruizhen Chu, Wanwan He, \\ Ji Huang, Jianfei Wang, and Hongsheng Zhang
}

State Key Laboratory of Crop Genetics \& Germplasm Enhancement, Nanjing Agricultural University, Nanjing 210095, China. Y. Wu and Y. Bao contributed equally to this work. Accepted for publication 18 May 2013.

\section{ABSTRACT}

Wu, Y., Bao, Y., Xie, L., Su, Y., Chu, R., He, W., Huang, J., Wang, J., and Zhang, H. 2013. Fine mapping and identification of blast resistance gene $P i-h k l$ in a broad-spectrum resistant japonica rice landrace. Phytopathology 103:1162-1168.

One Japonica rice landrace, Heikezijing, from the Taihu Lake region of China, exhibits broad-spectrum resistance to rice blast. As characterized in our previous research, a main-effect resistance $(R)$ gene, Pi-hkl, in Heikezijing against five isolates (GD10-279a, JS2004-141-1, JS2004185, JS90-78, and Hoku1) was roughly mapped on the long arm of chromosome 11. To fine map Pi-hkl, one recombinant inbred line (RIL), RIL72 $\left(\mathrm{F}_{2: 8}\right)$, from the cross between Heikezijing and blast-susceptible variety Suyunuo, was further crossed and backcrossed with Suyunuo to produce a $\mathrm{BC}_{1} \mathrm{~F}_{2}$ population of 477 individuals. Inoculation experiments with the representative isolate Hoku 1 indicated that RIL72 carries a single dominant $R$ gene for blast resistance. With the help of advanced $\mathrm{BC}_{1} \mathrm{~F}_{3}$ (915 plants), $\mathrm{BC}_{1} \mathrm{~F}_{4}$ (4,459 plants), and $\mathrm{BC}_{1} \mathrm{~F}_{5}$ (2,000 plants) mapping populations, $P i-h k 1$ was finally mapped to a $107-\mathrm{kb}$ region between molecular markers P3586 and ILP3, and co-segregated with the markers P4098, RM7654, and P4099. By sequence analysis of Heikezijing bacterial artificial chromosome clones covering Pi-hkl region, 16 predicted genes were identified within this region, including three nucleotide-binding site leucine-rich repeat candidate genes. These results provide essential information for cloning of $P i-h k l$ and its application in rice breeding for broad-spectrum blast resistance by marker-assisted selection.

Additional keywords: gene prediction.
Rice is one of the most important food crops, feeding $>50 \%$ of the world's population. Rice blast, caused by Magnaporthe oryzae, is one of the most devastating rice diseases worldwide. The annual loss of rice yield caused by blast was 10 to $30 \%$, estimated to be enough for feeding $\approx 60$ million people (36). Breeding efforts have aimed to introduce blast resistance $(R)$ genes into susceptible elite cultivars. However, resistant cultivars often remain effective for only a few years due to pathogenic variability of $M$. oryzae $(10,28)$. Therefore, breeding for cultivars that display broad-spectrum and durable resistance has become a priority in rice improvement programs throughout the world (17).

Over the past several years, genetic characteristic of blast resistance in rice has been extensively studied, and a number of $R$ genes have been documented $(2,33,45)$. Most of the reported $R$ genes are dominant and only pi21 and pi55 are recessive $(13,14)$. In total, $20 R$ genes have been cloned $(15,22,27,31,37,46,47)$, and some of them were organized into gene clusters, including Pi2 loci $($ Pi2/Piz-t/Pi9) $(30,48)$ and Pik loci (Pik/Pik-m/Pik-p/Pil) $(1,15,46,47)$. Of the cloned $R$ genes, 18 genes encode nucleotidebinding site leucine-rich repeat (NBS-LRR) proteins, except for $P i-d 2$, which encodes a B-lectin receptor kinase (9), and pi21, which encodes a proline-rich protein that includes a putative heavy metal-binding domain and putative protein-protein interaction motifs (13). It has been shown that at least six $R$ genes-

Corresponding authors: J. Wang and H. Zhang; E-mail addresses:

wangjf@njau.edu.cn and hszhang@njau.edu.cn

* The $\boldsymbol{e}$-Xtra logo stands for "electronic extra" and indicates that the online version contains one supplemental table.

http://dx.doi.org/10.1094/PHYTO-02-13-0044-R

(C) 2013 The American Phytopathological Society
Pil (24), Pi2 (6), Pi9 (21), Pi5 (18), Pi33 (4), and Pigm (11)— probably confer broad-spectrum resistance to a number of isolates or races from one or different countries. For instance, $\mathrm{Pi}$, located on the same region with $P i 2$, showed resistance to 43 isolates from 13 countries (21); Pi5 was a locus associated with resistance to at least 6 blast races from the Philippines and 26 isolates from Korea (18); and Pi33 showed resistance to $>2,000$ isolates originating from 55 countries (4).

In our previous research, it was found that Heikezijing, a japonica rice landrace from the Taihu region of China, exhibited broad-spectrum resistance to at least 300 isolates belonging to seven Chinese blast races $(35,40)$. In total, 22 quantitative trait loci (QTLs) conferring resistance to these isolates were identified and mapped on rice chromosomes $1,7,9,11$, and 12, including the main-effect locus qtll1-5-5, named $P i-h k l$, against five isolates, including GD10-279a(ZB5), JS2004-141-1(ZC5), JS2004185(ZE3), JS90-78(ZF1), and Hoku1 on chromosome 11, which could explain $74.34 \%$ phenotypic variance against blast isolate Hoku 1 (35). In this article, we reported that fine mapping of $\mathrm{Pi}$ $h k l$ and prediction of candidate genes by four backcross (BC) populations $\left(\mathrm{BC}_{1} \mathrm{~F}_{2}, \mathrm{BC}_{1} \mathrm{~F}_{3}, \mathrm{BC}_{1} \mathrm{~F}_{4}\right.$, and $\left.\mathrm{BC}_{1} \mathrm{~F}_{5}\right)$ derived from the cross between one recombinant inbred line (RIL), RIL72 $\left(\mathrm{F}_{2: 8}\right)$, from the cross Heikezijing $\times$ Suyunuo, and blast-susceptible variety Suyunuo.

\section{MATERIALS AND METHODS}

Plant materials and growth conditions. In our previous research, a population of RILs $\left(\mathrm{F}_{2: 8}\right)$ was constructed from a cross between a resistant landrace, Heikezijing, and a susceptible variety, Suyunuo (35). One RIL, RIL72, carrying the target gene $P i$ - $h k 1$ from Heikezijing, was selected as $R$ gene donor for developing fine-mapping populations. One $F_{2}$ population with 477 
plants, derived from a cross of RIL72 and the susceptible parent Suyunuo, were used for genetic analysis of resistance. Three advanced segregation populations $-\mathrm{BC}_{1} \mathrm{~F}_{3}$ (915 plants), $\mathrm{BC}_{1} \mathrm{~F}_{4}$ (4,459 plants), and $\mathrm{BC}_{1} \mathrm{~F}_{5}$ (2,000 plants) - derived from self-cross of the heterozygous $\mathrm{BC}_{1} \mathrm{~F}_{2}$ individuals were used for fine mapping of $P i-h k l$. The mapping population plants grown in the fields and leaves were sampled two times at the five- to six-leaf stage and mature grain stage for DNA extraction and marker analysis. According to the genotype results, we selected the recombinants for inoculation.

Rice seed were sown in plastic trays of 60 by 30 by $5 \mathrm{~cm}$ with sieved garden soil, as described by Wang et al. (40). In each tray, Suyunuo was used as the susceptible control. Plants were grown in a greenhouse at 24 to $30^{\circ} \mathrm{C}$ with a light and dark cycle of 16 and $8 \mathrm{~h}$, respectively, until they were at the four-leaf stage for disease evaluation. After disease evaluation, the leaves of susceptible plants were sampled for DNA extraction and marker analysis to conform the genotypes. For expression analysis of candidate genes, the leaves of Heikezijing seedlings inoculated by blast or water (control) were sampled as described (3).

Pathogen, inoculation, and disease evaluation. The $M$. oryzae isolate Hoku1 was used for all phenotypic analyses. Rice seedlings at the four-leaf stage were put into inoculation chambers and inoculated with a conidial suspension $\left(5 \times 10^{4}\right.$ conidia/ml $)$ as described by Wang et al. (40). The inoculated plants were kept in the chambers at $26^{\circ} \mathrm{C}$ with $95 \%$ relative humidity and darkness for $24 \mathrm{~h}$, and then transferred to a greenhouse $\left(28\right.$ to $30^{\circ} \mathrm{C}$, day and 20 to $22^{\circ} \mathrm{C}$, night) for disease incubation with $100 \%$ relative humidity by intermittently spraying water for 1 to 2 min every
$2 \mathrm{~h}$. Each line was inoculated in two independent experiments and three replications for each experiment.

Lesion types on rice leaves were scored after 1 week of inoculation according to the referred standard (24). Lesion scores of 0 to 5 were based on lesion type with appropriate reference of the disease area of the highest score of each plant, as described by Shi et al. (35). Individuals with scores 0,1 , and 2 were grouped as resistant and those with scores 3,4 , and 5 as susceptible.

Marker development and identification. Total DNA was extracted from the 3-week-old rice seedlings using the sodium dodecyl sulfate method (29). Three types of polymerase chain reaction (PCR)-based markers were used in this study. For simplesequence repeat (SSR) markers, the primer sets were adopted from the International Rice Microsatellite Initiative (http://www. gramene.org) (25). For further linkage analysis, intron length polymorphism (ILP) markers and insertion/deletion polymorphism (InDel) markers were developed in target region. ILP markers were designed around intronic regions which show higher polymorphism than exonic regions (42). For this type of marker, exon was first predicted by software tools GENSCAN (http://genes. mit.edu/GENSCAN.html) and softberry (http://linux1.softberry. com/berry.phtml). The predicted introns, $\approx 200$ to $500 \mathrm{bp}$, were considered to be putative ILP markers candidate sequences, and the flanking exon sequences were used for primer designing. InDel markers were developed according to the sequence comparison between of 93-11 (http://www.genomics.org.cn/) and Nipponbare (http://rgp.dna.affrc.go.jp/) in the target region by Pairwise BLAST (http://blast.ncbi.nlm.nih.gov/blast.cgi). The sequence where a large deletion between two subspecies exists is

TABLE 1. Information on polymerase chain reaction (PCR)-based markers used for mapping of Pi-hkl

\begin{tabular}{|c|c|c|c|c|c|}
\hline Marker & Type $^{\mathrm{a}}$ & Primer sequence $\left(5^{\prime}-3^{\prime}\right)$ & Product size (bp) expected & Anneal temperature $\left({ }^{\circ} \mathrm{C}\right)^{\mathrm{b}}$ & $\mathrm{Gel}^{\mathrm{c}}$ \\
\hline \multirow[t]{2}{*}{ RM27088 } & SSR & F: tgcaaagtgcaaagcgtaaagc & 169 & 56 & A \\
\hline & CSP & R: agcagcagcagtaggaacaagaagg & $\ldots$ & 0 & $\cdots$ \\
\hline RM27154 & SSR & F: tagtcgggcatctcctcttcc & 137 & 55 & A \\
\hline \multirow{2}{*}{ RM27189 } & SSR & F: ccgagcttaatttgcatctactgc & 93 & 58 & A \\
\hline & $\ldots$ & $\mathrm{R}:$ tgcagattgtggttggaaatgg & .. & $\cdots$ & $\ldots$ \\
\hline \multirow[t]{2}{*}{ RM27230 } & SSR & F: tccttccagtgatccagtttgg & 135 & 58 & $\mathrm{C}$ \\
\hline & $\ldots$ & R: cggaggtagtatattcttgctcttcc & $\ldots$ & & $\ldots$ \\
\hline \multirow[t]{2}{*}{ RM1233 } & SSR & F: atgggcacgtgtaattcattcg & 170 & 55 & A \\
\hline & & $\mathrm{R}:$ atcctcgaaagtaggagtaggaaagc & & & $\ldots$ \\
\hline \multirow[t]{2}{*}{ RM7221 } & SSR & F: ggatgccacatgtcgatttagg & 182 & 55 & A \\
\hline & & R: ctccctccgtttcacaatataagg & & & \\
\hline \multirow[t]{2}{*}{ ID2 } & InDel & F: atctgcacggccaagaaat & 339 & 58 & $\mathrm{C}$ \\
\hline & $\ldots$ & R: gagctccgccatgaacacc & $\ldots$ & $\ldots$ & $\ldots$ \\
\hline P3586 & InDel & F: ccctttaacacattccagcaa & 177 & 52 & A \\
\hline & $\ldots$ & $\mathrm{R}$ : ttacctaagcagctggcactgatgg & $\ldots$ & 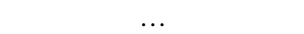 & $\ldots$ \\
\hline \multirow[t]{2}{*}{ P4099 } & InDel & F: aaaacattgaagttggcaaaga & 169 & 55 & A \\
\hline & & R: ggtgcaaggtttttctgagg & & & $\ldots$ \\
\hline \multirow[t]{2}{*}{ P4261 } & InDel & F: tgaatttatgaacaaaaacctttca & 199 & 52 & A \\
\hline & & R: atacccccaactgagtgcaa & $\ldots$ & & \\
\hline \multirow[t]{2}{*}{ ILP3 } & ILP & F: ctcaaggacaagaggtaattgc & 432 & 58 & B \\
\hline & & R: gctacttgctgattatctgtcgt & & & $\ldots$ \\
\hline \multirow[t]{2}{*}{ RM27296 } & SSR & F: gggtctttgtacacattcttgtgg & 519 & 53 & $\mathrm{C}$ \\
\hline & $\ldots$ & R: cttgaaggatgagcagtatctcg & $\ldots$ & $\ldots$ & $\ldots$ \\
\hline \multirow[t]{2}{*}{ RM27318 } & SSR & F: tgaactggacatgcctttatcc & 223 & 60 & A \\
\hline & & $\mathrm{R}:$ atgcgecttactttgttgtagg & & & \\
\hline \multirow[t]{2}{*}{ RM27342 } & SSR & F: tcatcttcatcggtgtcttcc & 98 & 55 & A \\
\hline & & R: ctgaaggaagttcaagaggatgg & & & . \\
\hline RM144 & SSR & F: catgttgtgcttgtcctactgc & 245 & 60 & A \\
\hline
\end{tabular}

${ }^{a} \mathrm{SSR}=$ simple-sequence repeat and InDel = insertion/deletion polymorphism.

${ }^{b}$ All of the PCR reactions were conducted as below: after preheating for $5 \mathrm{~min}$ at $94^{\circ} \mathrm{C}, 35 \mathrm{PCR}$ cycles $\left(40 \mathrm{~s}\right.$ at $94^{\circ} \mathrm{C}, 40 \mathrm{~s}$ at the corresponding temperature described above, and $40 \mathrm{~s}$ at $72^{\circ} \mathrm{C}$ ) were followed by $10 \mathrm{~min}$ at $72^{\circ} \mathrm{C}$.

${ }^{c} \mathrm{~A}=8 \%$ acrylamide, $\mathrm{B}=6 \%$ acrylamide, and $\mathrm{C}=2 \%$ agarose. 
considered to be a candidate sequence for a putative InDel marker. All primers of these new markers were designed by Primer Premier 5.0 (PREMIER Bio-software International) (http://www.premierbiosoft.com). Information about primer sequences and PCR conditions is listed in Table 1.

Construction of genetic and physical maps. In total, 915 $\mathrm{BC}_{1} \mathrm{~F}_{3}$ susceptible individuals were used to construct a genetic map of the $R$ gene of RIL72 with SSR markers by recessive-class analysis methods (Fig. 1A) (49). In total, 6,459 plants of $\mathrm{BC}_{1} \mathrm{~F}_{4}$ $(4,459)$ and $\mathrm{BC}_{1} \mathrm{~F}_{5}(2,000)$ were used for constructing a fine genetic linkage map on the basis of recombination frequencies between adjacent loci (Fig. 1B).

For constructing a physical map, a BAC library of Heikezijing was constructed in pIndigoBAC-5, as described (39), and screened with $P i$ - $h k l$ linked markers as described (5). Three positive clones (numbers 66P14, 242, and 91C13) covering P3586 and ILP3 markers were obtained and sequenced by a shotgun sequencing method (12). Sequences of these three clones were analyzed and aligned by the bio-software tool Pairwise BLAST (http://blast. ncbi.nlm.nih.gov/blast.cgi) to construct the BAC contig spanning the $P i$-hkl locus (Fig. 1C).

Candidate gene prediction and analysis. Open reading frames (ORFs) were predicted by GENSCAN (http://genes.mit. edu), FGENSH (http://linux1.softberry.com/), and Rice Genome Automated Annotation System (RiceGAAS) (http://rgp.dna. affrc.go.jp) software (32). The DNA and full-length cDNA of 16 predicted genes from two parents were amplified by PCR methods and sequenced (Invitrogen, Shanghai). Then, DNA and cDNA sequences were used to search the nucleotide collection $(\mathrm{nr} / \mathrm{nt})$ and expressed sequence tag (EST) database by BLAST tools (http://www.ncbi.nlm.nih.gov/blast).
The expression patterns of 16 candidate genes were detected by quantitative real-time reverse-transcription (RT)-PCR methods as described by Huang et al. (16). The fold change in cDNA (target candidate gene) relative to the reference gene (18s-rRNA) was determined by the comparative cycle threshold method (23). Relative quantification relates the PCR signal of the target transcript in inoculated rice seedlings to that of uninoculated rice plants. The primers for 16 candidate genes and 18s-rRNA in quantitative realtime RT-PCR assay are shown in Supplemental Table 1.

\section{RESULTS}

Genetic analyses. One $\mathrm{BC}_{1} \mathrm{~F}_{2}$ population consisting of 477 individuals, derived from a backcross of one blast-resistant line, RIL72, carrying Pi-hkl locus and susceptible parent Suyunuo were inoculated with the isolate Hoku1. The segregation ratio of the resistant individuals to susceptible individuals (R/S) showed 3:1 (350R:127S) $\left(\chi^{2}=0.67, P=0.41\right)$, indicating that RIL72 carries a single dominant $R$ gene, $P i$ - $h k l$, that conferred resistance to isolate Hoku1.

Mapping of Pi-hk1. In all, 46 SSR markers located in the region of target gene were selected and identified for their genetic polymorphisms between two parents, Heikezijing and Suyunuo. Seven markers (RM144, RM27342, RM27318, RM7654, RM27248, RM27230, and RM27189) showed polymorphisms between two parents. In total, 915 susceptible individuals selected from a $\mathrm{BC}_{1} \mathrm{~F}_{3}$ population were subjected to linkage analysis with these SSR markers. There were 15, 15, and 2 recombinants that could be identified by RM144, RM27342, and RM27318, respectively, toward the telomeric side and 11, 9, and 3 recombinants identified by RM27189, RM27230, and RM27248, respectively,

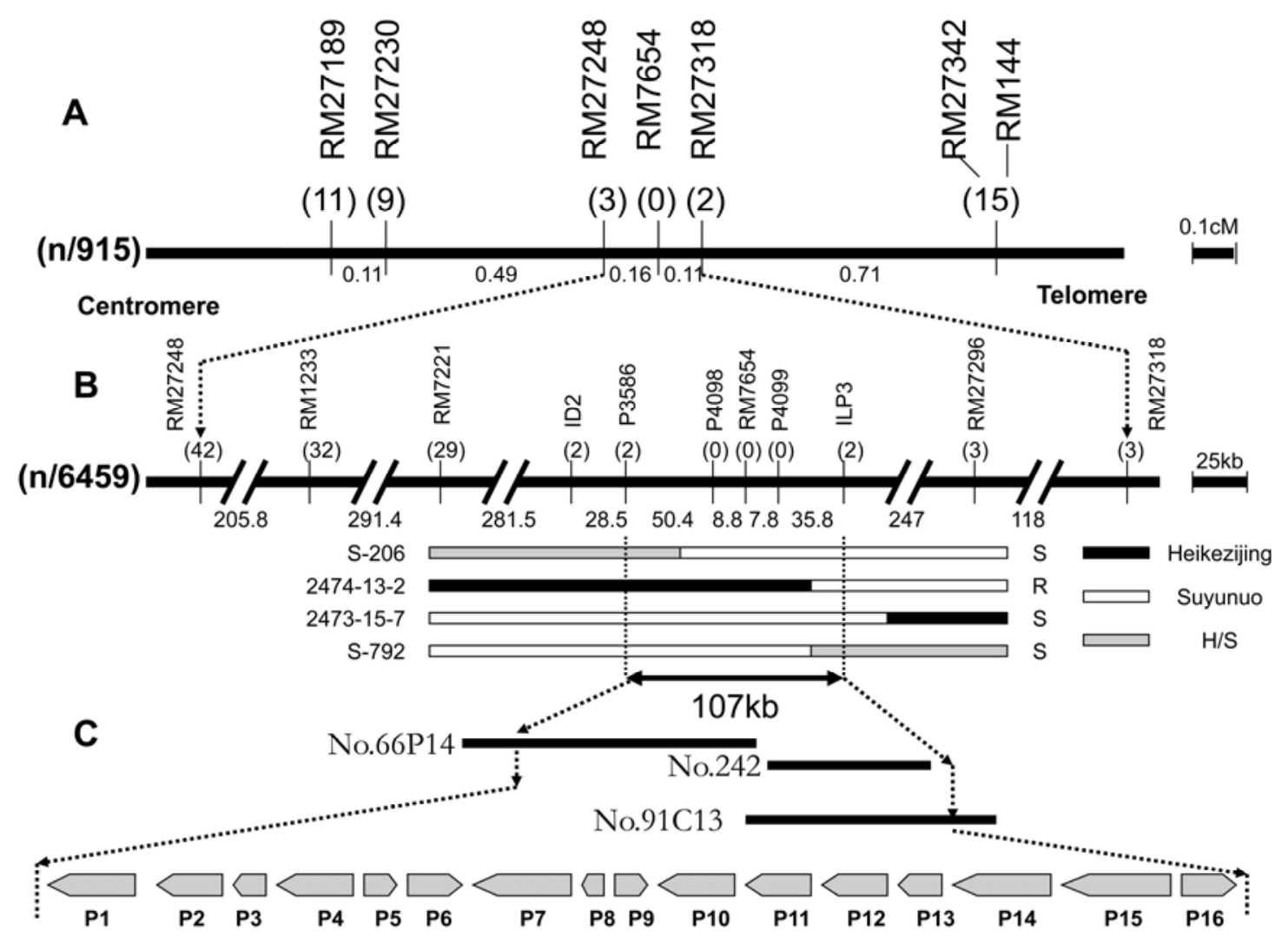

Fig. 1. Genetic and physical maps of the region of the Pi-hkl locus. A, Genetic map of the resistance gene, Pi-hkl. Numbers in parenthesis are the recombination events in the mapping populations; digits below this map are relative genetic distances in centimorgans. B, Physical map of Pi-hkl, constructed from the 'Nipponbare' genomic sequence and sequenced BAC clones of 'Heikezijing'. Numbers in parenthesis are the recombination events in the mapping populations. Numbers below the map are physical distance. C, Contig map and candidate genes of the Pi-hkl locus. Short horizontal lines represent BAC clones of Heikezijing. These clones are anchored by the corresponding markers linked to the Pi-hkl locus. Arrows represent open reading frames (ORFs) predicted in the Pi-hkl region by the Rice Genome Automated Annotation System. 
on the centromeric side. No recombinants were detected by RM7654, indicating that RM7654 co-segregated with the $R$ gene. Based on these results, Pi-hkl might be flanked by markers RM27248 and RM27318. The genetic distances of Pi-hkl to RM144, RM27342, RM27318, RM27248, RM27230, and RM27189 were $0.82,0.82,0.11,0.16,0.65$, and 0.76 centimorgans (cM), respectively (Fig. 1A).

RM27248 and RM27318 were tested in the 4,459 individuals of $\mathrm{BC}_{1} \mathrm{~F}_{4}$ and 2,000 of $\mathrm{BC}_{1} \mathrm{~F}_{5}$ populations and 45 recombinants were selected in this region. Within the interval flanked by RM27248 and RM27318, eight polymorphic markers, including three SSR makers (RM7221, RM1233, and RM27296) and five ILP or InDel markers (ILP3, ID2, P3586, P4098, and P4099) developed in this research were tested in 45 recombinants. There were $32,29,2$, and 2 recombinants that could be detected by RM1233, RM7221, ID2, and P3586, respectively, on the centromeric side, and 3 and 2 recombinants detected by RM27296 and ILP3, respectively, on the telomeric side. There were no recombinants detected by $\mathrm{P} 4098$ and P4099. In all, 45 recombinants were inoculated for fine-mapping $P i$ - $h k l$. Therefore, $P i$ - $h k l$ was finally delimited into an interval flanked by P3586 and ILP3 and cosegregated with P4098, RM7654, and P4099. The genetic region spanning the $P i-h k l$ locus was estimated to be $0.031 \mathrm{cM}$ in length (Fig. 1B).

Prediction of candidate genes. To physically cover the Pi-hkl locus, a BAC library of Heikezijing was constructed, which included $\approx 39,936$ clones with an average DNA insert size of 70 $\mathrm{kb}$, corresponding to 6.5 genome equivalents (unpublished data). By screening with co-segregating markers P3586, RM7654, and ILP3, three positive clones (numbers 66P14, 242, and 91C13) spanning the $P i-h k l$ region were obtained and sequenced. The results showed that the physical distance between P3586 and ILP3 in Heikezijing was $\approx 107 \mathrm{~kb}$ (Fig. 1C).

Sequence analyzed by GENSCAN (http://genes.mit.edu), FGENSH (http://linux1.softberry.com/), and RiceGAAS (http:// rgp.dna.affrc.go.jp) software suggests that the region flanked by P3586 and ILP3 contains 16 predicted genes, P1 to P16. They were used to search the full-length cDNA and EST database; $P 3$ and $P 8$ had no hits to ESTs and unknown functions and the other 14 genes had hits to full-length cDNA or EST. Eight genes $(P 2$, $P 4, P 7, P 9, P 13, P 14, P 15$, and P16) showed sequence differences between two parents (Table 2). In order to narrow down the range of candidate genes, real-time RT-PCR was performed to examine the expression pattern of candidate genes in Heikezijing seedlings induced by Hoku1. The results showed that $P 1, P 2$, $P 11$, and $P 14$ were not expressed before or after inoculation; $P 3$, $P 4$, and $P 8$ were not induced by inoculation; $P 5, P 6, P 7, P 9$, and $P 10$ were slightly induced $(2.1-, 2.2-, 3.5-, 2.1-$, and 1.6-fold, respectively) by inoculation; and $P 12, P 13, P 15$, and $P 16$ were strongly induced (6.1-, 80.5-, 8.2-, and 31.5-fold, respectively) by inoculation (Fig. 2). According to these results, five genes ( $P 7$, $P 9, P 13, P 15$, and $P 16$ ), including three encoded NBS-LRR disease resistance proteins, might be considered to be the candidates of the $P i-h k l$ gene.

\section{DISCUSSION}

As characterized in the previous study, $P i-h k l$, conferring resistance to blast in landrace Heikezijing, was roughly mapped between RM27187 and RM27381 on the long arm of rice chromosome 11 (35). In this study, Pi-hkl was mapped in the 107-kb region between P3586 and ILP3 co-segregated with markers P4098, RM7654, and P4099 on rice chromosome 11. Five other blast $R$ genes-Pikh, Pik-m, Pik, Pik-p, and Pil-were reported to locate near this region $(15,20,34,41)$. In order to distinguish $P i$ $h k l$ from them, the six genes were integrated into the same chromosome physical map according to their linked markers located on the Nipponbare sequence (Fig. 3). The results showed that the distance between the region flanked by P3586 and ILP3 and the region of $P i-k h$ was $2,334 \mathrm{~kb}$ and to the Pik cluster was $114 \mathrm{~kb}$. In our previous work, these five $R$ genes showed significantly different resistance-spectra with Pi-hkl (40). All of these results suggested that $P i-h k l$ is a new blast $R$ gene.

With help of four populations- $-\mathrm{BC}_{1} \mathrm{~F}_{2}$ (477 plants), $\mathrm{BC}_{1} \mathrm{~F}_{3}(915$ plants), $\mathrm{BC}_{1} \mathrm{~F}_{4}$ (4,459 plants), and $\mathrm{BC}_{1} \mathrm{~F}_{5}$ (2,000 plants) - Pi- $h k 1$ was mapped in a $107-\mathrm{kb}$ region. Recombinant events were rarely detected in the $P i-h k 1$ region. In the interval between RM7654 and RM27318, only three recombinants were found in 6,459 plants. According to $\mathrm{Wu}$ and Tanksley's method, the physical/ genetic $(\mathrm{P} / \mathrm{G})$ ratio between RM7654 and RM27318 was estimated as $1,759,431.6 \mathrm{~kb} / \mathrm{cM}$, which was much higher than the average $\mathrm{P} / \mathrm{G}$ ratio of 260 to $280 \mathrm{~kb} / \mathrm{cM}$ estimated in the rice genome (44). There was even no recombination break point observed in the interval spanned by RM27342 and RM144. Re-

TABLE 2. Candidate genes at the Pi-hkl region in one parent Heikezijing

\begin{tabular}{|c|c|c|c|c|c|c|}
\hline Genes $^{\mathrm{a}}$ & $\begin{array}{l}\text { TIGR/IRGSP } \\
\text { gene identity }\end{array}$ & Gene products ${ }^{\mathrm{b}}$ & Conserved domain & $\mathrm{cDNA}$ or $\mathrm{EST}^{\mathrm{c}}$ & $\mathrm{aa}^{\mathrm{d}}$ & Diff. $^{\mathrm{e}}$ \\
\hline$P 1$ & Os11g0681600 & Cysteine-rich receptor-like protein kinase & Catalytic domain & AK243250 & 625 & No \\
\hline$P 2$ & Os11g0622600 & $\mathrm{BTB} / \mathrm{POZ}$ domain like protein & BTB/POZ domain & $\begin{array}{l}\text { AU094686(EST); } \\
\text { AU094687(EST) }\end{array}$ & 344 & Yes \\
\hline$P 3$ & None & Unknown Protein & None & No EST & 143 & No \\
\hline P4 & Os11g0682000 & Cadmium tolerance factor & None & AK241956 & 688 & Yes \\
\hline P5 & Os02g0764100 & AP2 domain-containing transcription factor & AP2 domain & AK066197 & 182 & No \\
\hline P6 & Os11g0682300 & Nucleic acid binding protein & Nucleotide-binding & AK066311 & 613 & No \\
\hline$P 9$ & Os11g0683600 & Unknown Protein & None & AK119461 & 167 & Yes \\
\hline$P 10$ & Os11g0683500 & Putative $\beta$-glycosidase & None & AK067619 & 647 & No \\
\hline P11 & Os11g0683700 & Pectin lyase fold domain containing protein & Pectin lyase fold domain & AK072863 & 399 & No \\
\hline P12 & Os11g0683800 & Pectin lyase fold domain containing protein & Pectin lyase fold domain & AK070275 & 426 & No \\
\hline$P 13$ & Os11t0684000 & Myb transcription factor & Myb-type HTH DNA-binding domain & AK069082 & 285 & Yes \\
\hline P14 & Os01g0265300 & Transponson & Transponson & AK288785 & 1,102 & Yes \\
\hline$P 15$ & Os11t0684100 & NBS-LRR disease resistance protein & NBS-LRR domain & AK066053 & 1,361 & Yes \\
\hline
\end{tabular}

a Predicted genes.

${ }^{\mathrm{b}}$ NBS-LRR = nucleotide-binding site leucine-rich repeat.

${ }^{c}$ Full-length cDNA or expressed sequence tag (EST).

${ }^{d}$ Number of amino acids.

${ }^{\mathrm{e}}$ No and Yes indicate that there is no sequence difference or is a sequence difference, respectively, between two parents detected by polymerase chain reaction amplification and sequencing. 
cently, distorted segregation has frequently been identified in some regions of the rice chromosome $(7,43)$. Four $R$ genes were reported in regions with low recombination, such as Pi5 (18), Pi37 (8), Pi-km (20), and Pita2 (26). The crossover suppression might be explained by two reasons. The first is the lack of pairing and subsequent strand exchange between homologous regions in two parents, which can be supported by the fact that some of the markers we developed only amplified one of the parents. The second is a segregation distortion locus (19), such as when the gamete gene and sterile gene may be located in the region RM27342 and RM144, because there was no recombination event observed in this region. The impact of the distortion will depend on the linkage distance between the distorted loci and target gene; the closer distance showed more serious distorted segregation (19).

Sequence analysis of the BAC contig of Heikezijing covering the $P i-h k 1$ region between P3586 and ILP3 identified 16 genes. The sequences comparing the promoter and gene region, EST
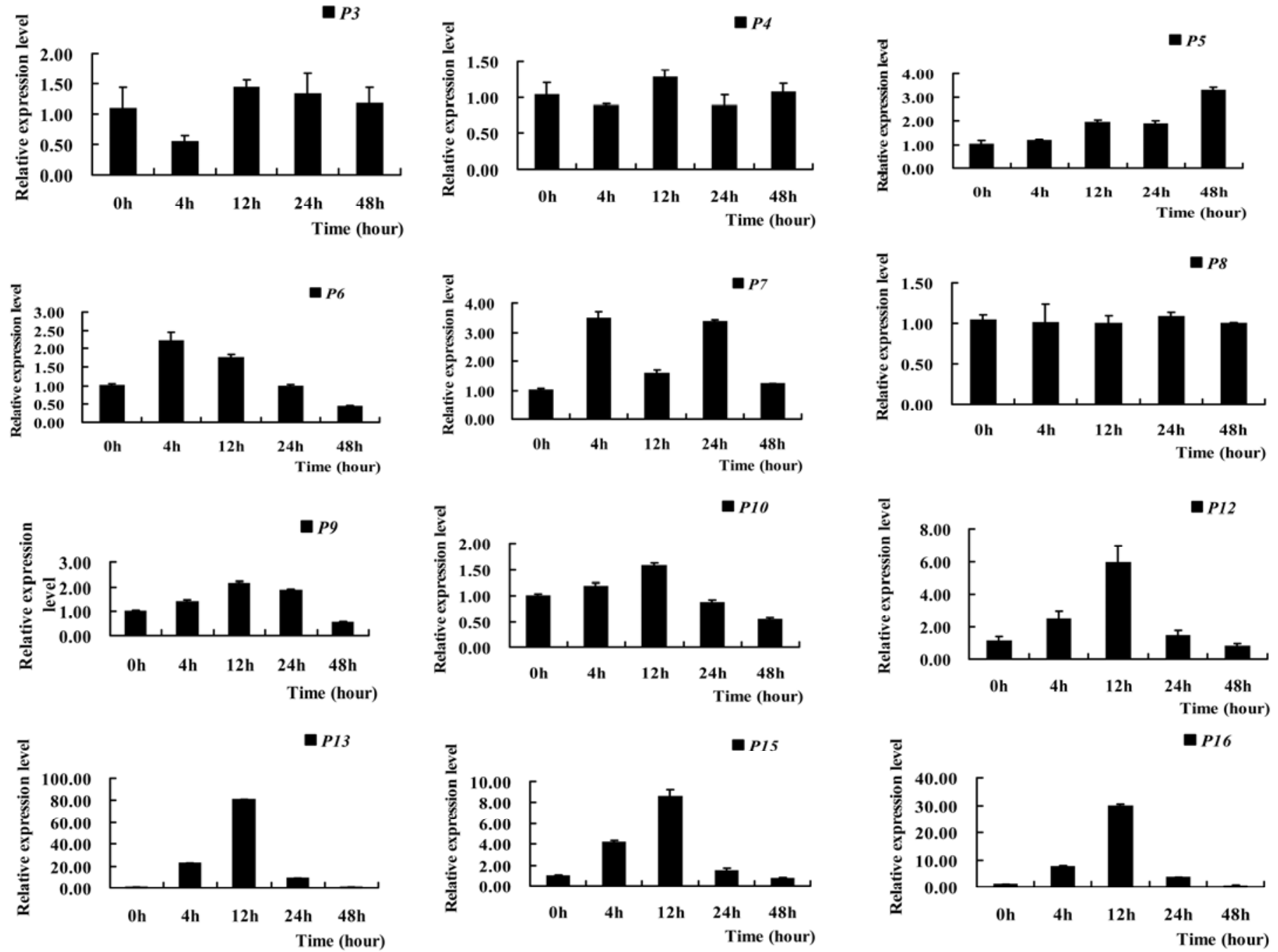

Fig. 2. Real-time polymerase chain reaction analysis for the expression patterns of candidate genes in Heikezijing induced by inoculation Hoku1. 18S-rRNA was used as an internal control. Data represent means and standard errors of three replicates.

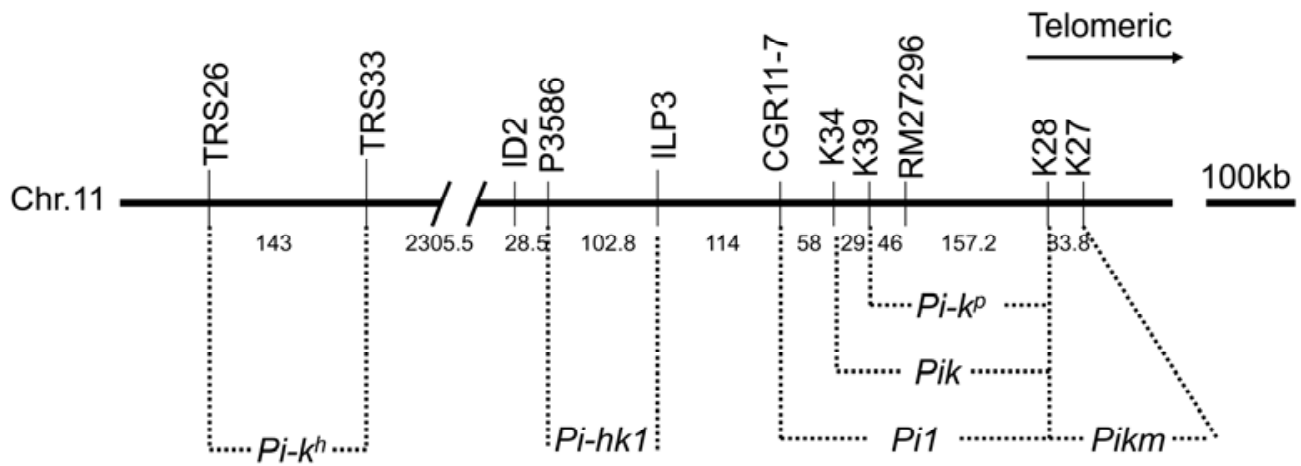

Fig. 3. Integrated physical mapping of six resistance genes (Pikh, Pil, Pik, Pik-p, Pik-m, and Pi-hk1), which were mapped on telemetric region of chromosome 11. Positions of the resistance genes and markers were integrated on the basis of data from the following references: Pi-hk1 (this article), Pikh (34), Pil (15), Pik and Pik-p (41), and Pikm (20).Markers used in this study and their physical distances were mapped below the chromosome 
database searching, and expression patterns analysis of these genes showed that only five genes could be the potential candidate genes. They encode an unknown protein (P9), an Myb transcription factor $(P 13)$, and three NBS-LRR disease resistance proteins $(P 7, P 15$, and $P 16)$, respectively. Especially three NBS-LRR domain proteins (P7, P15, and P16) are most likely to have plant resistance function because an NBS-LRR disease resistance protein had been demonstrated to be involved in plant disease resistance or associated with cell death in animals (38). In this report, we only considered the expressed genes because our future work will focus on identifying which candidate genes represent the broad-spectrum resistance of $P i-h k l$ to blast using Agrobacterium-mediated transformation technology.

\section{ACKNOWLEDGMENTS}

This research has been supported by grants from the National Key Project for Transgenic Crops (2009ZX08009-040B and 2011ZX08009003), the Natural Science Foundation of China (30771324, 30900888, and 31171516), and Natural Science Foundation of Jiangsu province (BK2009306). We thank Z.-Y. Chen and Y.-F. Liu for kindly providing all of the blast isolates and G.-Y. Zeng and L.-L. Dang for their experimental help.

\section{LITERATURE CITED}

1. Ashikawa, I., Hayashi, N., Yamane, H., Kanamori, H., Wu, J., Matsumoto, T., Ono, K., and Yano, M. 2008. Two adjacent nucleotide-binding siteleucine-rich repeat class genes are required to confer Pikm-specific rice blast resistance. Genetics 180:2267-2276.

2. Ballini, E., Morel, J. B., Droc, G., Price, A., Courtois, B., Notteghem, J. L., and Tharreau, D. 2008. A genome-wide meta-analysis of rice blast resistance genes and quantitative trait loci provides new insights into partial and complete resistance. Mol. Plant-Microbe Interact. 21:859-868.

3. Bao, Y. M., Wang, J. F., Huang, J., and Zhang, H. S. 2008. Cloning and characterization of three genes encoding Qb-SNARE proteins in rice. Mol. Genet. Genomics 279:291-301.

4. Berruyer, R., Adreit, H., Milazzo, J., Gaillard, S., Berger, A., Dioh, W., Lebrun, M. H., and Tharreau, D. 2003. Identification and fine mapping of Pi33, the rice resistance gene corresponding to the Magnaporthe grisea avirulence gene ACE1. Theor. Appl. Genet. 107:1139-1147.

5. Bryan, G. T., Wu, K. S., Farrall, L., Jia, Y. L., Hershery, H. P., McAdams, S. A., Faulk, K. N., Donaldson, G. K., Tarchini, R., and Valent, B. 2000. A single amino acid difference distinguishes resistant and susceptible alleles of the rice blast resistance gene Pi-ta. Plant Cell 12:2033-2045.

6. Chen, D., Zeigler, R., Ahn, S., and Nelson, R. 1996. Phenotypic characterization of the rice blast resistance gene Pi-2 (t). Plant Dis. 80:52-56.

7. Chen, M., Presting, G., Barbazuk, W. B., Goicoechea, J. L., Blackmon, B., Fang, G., Kim, H., Frisch, D., Yu, Y., Sun, S., Higingbottom, S., Phimphilai, J., Phimphilai, D., Thurmond, S., Gaudette, B., Li, P., Liu, J., Hatfield, J., Main, D., Farrar, K., Henderson, C., Barnett, L., Costa, R., Williams, B., Walser, S., Atkins, M., Hall, C., Budiman, M. A., Tomkins, J. P., Luo, M., Bancroft, I., Salse, J., Regad, F., Mohapatra, T., Singh, N. K., Tyagi, A. K., Soderlund, C., Dean, R. A., and Wing, R. A. 2002. An integrated physical and genetic map of the rice genome. Plant Cell 14:537-545.

8. Chen, S., Wang, L., Que, Z., Pan, R., and Pan, Q. 2005. Genetic and physical mapping of $P i 37(t)$, a new gene conferring resistance to rice blast in the famous cultivar St. No. 1. Theor. Appl. Genet. 111:1563-1570.

9. Chen, X., Shang, J., Chen, D., Lei, C., Zou, Y., Zhai, W., Liu, G., Xu, J., Ling, Z., Cao, G., Ma, B., Wang, Y., Zhao, X., Li, S., and Zhu, L. 2006. A B-lectin receptor kinase gene conferring rice blast resistance. Plant J. 46:794-804.

10. Dean, R. A., Talbot, N. J., Ebbole, D. J., Farman, M. L., Mitchell, T. K., Orbach, M. J., Thon, M., Kulkarni, R., Xu, J. R., Pan, H., Read, N. D., Lee, Y. H., Carbone, I., Brown, D., Oh, Y. Y., Donofrio, N., Jeong, J. S., Soanes, D. M., Djonovic, S., Kolomiets, E., Rehmeyer, C., Li, W., Harding, M., Kim, S., Lebrun, M. H., Bohnert, H., Coughlan, S., Butler, J., Calvo, S., Ma, L. J., Nicol, R., Purcell, S., Nusbaum, C., Galagan, J. E., and Birren, B. W. 2005. The genome sequence of the rice blast fungus Magnaporthe grisea. Nature 434:980-998.

11. Deng, Y., Zhu, X., Shen, Y., and He, Z. 2006. Genetic characterization and fine mapping of the blast resistance locus Pigm (t) tightly linked to Pi2 and $P i 9$ in a broad-spectrum resistant Chinese variety. Theor. Appl. Genet. 113:705-713.

12. Fleischmann, R. D., Adams, M. D., White, O., Clayton, R. A., Kirkness, E. F., Kerlavage, A. R., Bult, C. J., Tomb, J. F., Dougherty, B. A., and
Merrick, J. M. 1995. Whole-genome random sequencing and assembly of Haemophilus influenzae Rd. Science 269:496-512.

13. Fukuoka, S., Saka, N., Koga, H., Ono, K., Shimizu, T., Ebana, K., Hayashi, N., Takahashi, A., Hirochika, H., Okuno, K., and Yano, M. 2009. Loss of function of a proline-containing protein confers durable disease resistance in rice. Science 325:998-1001.

14. He, X. Y., Liu, X. Q., Wang, L., Lin, F., Cheng, Y. S., Chen, Z. M., Liao, Y. P., and Pan, Q. H. 2012. Identification of the novel recessive gene pi55 (t) conferring resistance to Magnaporthe oryzae. Sci. China Life Sci. 55:141-149.

15. Hua, L., Wu, J., Chen, C., Wu, W., He, X., Lin, F., Wang, L., Ashikawa, I., and Matsumoto, T. 2012. The isolation of Pil, an allele at the Pik locus which confers broad spectrum resistance to rice blast. Theor. Appl. Genet. 125:1047-1055.

16. Huang, J., Wang, M. M., Jiang, Y., Bao, Y. M., Huang, X., Sun, H., Xu, D. Q., Lan, H. X., and Zhang, H. S. 2008. Expression analysis of rice A20/AN1-type zinc finger genes and characterization of ZFP177 that contributes to temperature stress tolerance. Gene 420:135-144.

17. Hulbert, S. H., Webb, C. A., Smith, S. M., and Sun, Q. 2001. Resistance gene complexes: Evolution and utilization. Annu. Rev. Phytopathol. 39:285-312.

18. Jeon, J. S., Chen, D., Yi, G. H., Wang, G. L., and Ronald, P. C. 2003. Genetic and physical mapping of Pi5(t), a locus associated with broadspectrum resistance to rice blast. Mol. Genet. Genomics 269:280-289.

19. Kakani, A., Saha, S., Sapra, V., Zipf, A., and Stelly, D. 1999. Genetic mechanism and chromosomal location of pollen specific gene(s) in Gossypium. Crop Sci. 39:668-673.

20. Li, L. Y., Wang, L., Jing, J. X., Li, Z. Q., Lin, F., Huang, L. F., and Pan, Q. H. 2007. The Pik ${ }^{m}$ gene, conferring stable resistance to isolates of Magnaporthe oryzae, was finely mapped in a crossover-cold region on rice chromosome 11. Mol. Breed. 20:179-188.

21. Liu, G., Lu, G., Zeng, L., and Wang, G. L. 2002. Two broad-spectrum blast resistance genes, $P i 9(t)$ and $P i 2(t)$, are physically linked on rice chromosome 6. Mol. Genet. Genomics 267:472-480.

22. Liu, J., Wang, X., Mitchell, T., Hu, Y., Liu, X., Dai, L., and Wang, G. L. 2010. Recent progress and understanding of the molecular mechanisms of the rice-Magnaporthe oryzae interaction. Mol. Plant Pathol. 11:419-427.

23. Livak, K. J., and Schmittgen, T. D. 2001. Analysis of relative gene expression data using real-time quantitative PCR and the $2^{-\Delta \Delta C T}$ method. Methods 25:402-408.

24. Mackill, D., and Bonman, J. 1992. Inheritance of blast resistance in nearisogenic lines of rice. Phytopathology 82:746-749.

25. McCouch, S. R., Teytelman, L., Xu, Y., Lobos, K. B., Clare, K., Walton, M., Fu, B., Maghirang, R., Li, Z., and Xing, Y. 2002. Development and mapping of 2240 new SSR markers for rice (Oryza sativa L.). DNA Res. 9:199-207.

26. Nakamura, S., Asakawa, S., Ohmido, N., Fukui, K., Shimizu, N., and Kawasaki, S. 1997. Construction of an $800-\mathrm{kb}$ contig in the nearcentromeric region of the rice blast resistance gene Pi-ta2 using a highly representative rice BAC library. Mol. Gen. Genet. 254:611-620.

27. Okuyama, Y., Kanzaki, H., Abe, A., Yoshida, K., Tamiru, M., Saitoh, H., Fujibe, T., Matsumura, H., Shenton, M., Galam, D. C., Undan, J., Ito, A., Sone, T., and Terauchi, R. 2011. A multifaceted genomics approach allows the isolation of the rice Pia-blast resistance gene consisting of two adjacent NBS-LRR protein genes. Plant J. 66:467-479.

28. Ou, S. H. 1979. Breeding rice for resistance to blast, a critical view. Pages 79-137 in: Proc. Rice Blast Workshop. IRRI, Manila, Philippines.

29. Pich, U., and Schubert, I. 1993. Midiprep method for isolation of DNA from plants with a high content of polyphenolics. Nucleic Acids Res. 21:3328.

30. Qu, S., Liu, G., Zhou, B., Bellizzi, M., Zeng, L., Dai, L., Han, B., and Wang, G. L. 2006. The broad-spectrum blast resistance gene Pi9 encodes a nucleotide-binding site-leucine-rich repeat protein and is a member of a multigene family in rice. Genetics 172:1901-1914.

31. Rai, A. K., Kumar, S. P., Gupta, S. K., Gautam, N., Singh, N. K., and Sharma, T. R. 2011. Functional complementation of rice blast resistance gene Pi-k ${ }^{h}$ (Pi54) conferring resistance to diverse strains of Magnaporthe oryzae. J. Plant Biochem. Biot. 20:55-65.

32. Sakata, K., Nagamura, Y., Numa, H., Antonio, B. A., Nagasaki, H., Idonuma, A., Watanabe, W., Shimizu, Y., Horiuchi, I., Matsumoto, T., Sasaki, T., and Higo, K. 2002. RiceGAAS: An automated annotation system and database for rice genome sequence. Nucleic Acids Res. 30:98-102.

33. Sharma, T., Rai, A., Gupta, S., Vijayan, J., Devanna, B., and Ray, S. 2012. Rice blast management through host-plant resistance: Retrospect and prospects. Agric. Res. 1:37-52.

34. Sharma, T. R., Madhav, M. S., Singh, B. K., Shanker, P., Jana, T. K., Dalal, V., Pandit, A., Singh, A., Gaikwad K., Upreti H. C., and Singh N. K. 2005. High-resolution mapping, cloning and molecular characterization of the Pi-k $k^{h}$ gene of rice, which confers resistance to Magnaporthe grisea. Mol. Gen. Genomics 274:569-578. 
35. Shi, X., Wang, J., Bao, Y., Li, P., Xie, L., Huang, J., and Zhang, H. 2010. Identification of the quantitative trait loci in japonica rice landrace Heikezijing responsible for broad-spectrum resistance to rice blast. Phytopathology 100:822-829.

36. Skamnioti, P., and Gurr, S. J. 2009. Against the grain: Safeguarding rice from rice blast disease. Trends Biotechnol. 27:141-150.

37. Takahashi, A., Hayashi, N., Miyao, A., and Hirochika, H. 2010. Unique features of the rice blast resistance Pish locus revealed by large scale retrotransposon-tagging. BMC Plant Biol. 10:175.

38. van der Biezen, E. A., and Jones, J. D. 1998. The NB-ARC domain: A novel signalling motif shared by plant resistance gene products and regulators of cell death in animals. Curr. Biol. 8:R226-227.

39. Wang, G. L., Holsten, T. E., Song, W. Y., Wang, H. P., and Ronald, P. C. 1995. Construction of a rice bacterial artificial chromosome library and identification of clones linked to the $\mathrm{Xa}-21$ disease resistance locus. Plant J. 7:525-533.

40. Wang, J. F., He, X. J., Zhang, H. S., and Chen, Z. 2002. Genetic analysis of blast resistance in japonica rice landrace heikezijing from Taihu region. Yi Chuan Xue Bao 29:803-807.

41. Wang, L., Xu, X., Lin, F., and Pan, Q. 2009. Characterization of rice blast resistance genes in the Pik cluster and fine mapping of the Pik-p locus. Phytopathology 99:900-905.

42. Wei, H., Fu, Y., and Arora, R. 2005. Intron-flanking EST-PCR markers: From genetic marker development to gene structure analysis in Rhododendron. Theor. Appl. Genet. 111:1347-1356.

43. Wu, J., Mizuno, H., Hayashi-Tsugane, M., Ito, Y., Chiden, Y., Fujisawa, M., Katagiri, S., Saji, S., Yoshiki, S., Karasawa, W., Yoshihara, R., Hayashi,
A., Kobayashi, H., Ito, K., Hamada, M., Okamoto, M., Ikeno, M., Ichikawa, Y., Katayose, Y., Yano, M., Matsumoto, T., and Sasaki, T. 2003. Physical maps and recombination frequency of six rice chromosomes. Plant $\mathrm{J}$. 36:720-730.

44. Wu, K. S., and Tanksley, S. D. 1993. PFGE analysis of the rice genome: Estimation of fragment sizes, organization of repetitive sequences and relationships between genetic and physical distances. Plant Mol. Biol. 23:243-254

45. Yang, Q., Lin, F., Feng, S., Wang, L., and Pan, Q. 2009. Recent progress on molecular mapping and cloning of blast resistance genes in rice (Oryza sativa L.). Sci. Agric. Sin. 42:1601-1615.

46. Yuan, B., Zhai, C., Wang, W., Zeng, X., Xu, X., Hu, H., Lin, F., Wang, L., and Pan, Q. 2011. The Pik-p resistance to Magnaporthe oryzae in rice is mediated by a pair of closely linked CC-NBS-LRR genes. Theor. Appl. Genet. 122:1017-1028.

47. Zhai, C., Lin, F., Dong, Z., He, X., Yuan, B., Zeng, X., Wang, L., and Pan, Q. 2011. The isolation and characterization of Pik, a rice blast resistance gene which emerged after rice domestication. New Phytol. 189:321-334.

48. Zhou, B., Qu, S., Liu, G., Dolan, M., Sakai, H., Lu, G., Bellizzi, M., and Wang, G. L. 2006. The eight amino-acid differences within three leucinerich repeats between $\mathrm{Pi} 2$ and Piz-t resistance proteins determine the resistance specificity to Magnaporthe grisea. Mol. Plant-Microbe Interact. 19:1216-1228.

49. Zhu, M., Wang, L., and Pan, Q. 2004. Identification and characterization of a new blast resistance gene located on rice chromosome 1 through linkage and differential analyses. Phytopathology 94:515-519. 